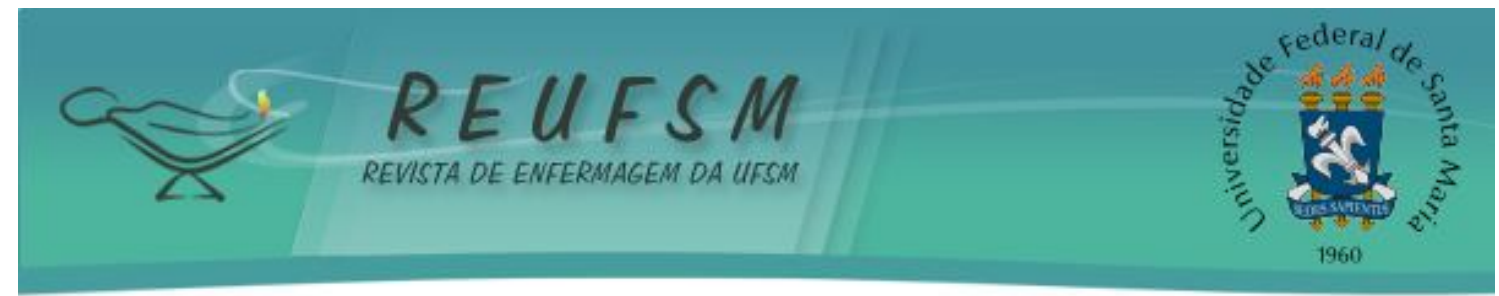

RELATO DE EXPERIÊNCIA

\title{
EDUCAÇÃO POPULAR EM SAÚDE NO CURSO DE GRADUAÇÃO EM ENFERMAGEM: CONSTRUÇÃO DE ESPAÇOS CURRICULARES PARTICIPATIVOS
}

\section{POPULAR HEALTH EDUCATION IN NURSING DEGREE COURSE: THE CONST RUCTION OF PART ICIPATIVES CURRICULARIES SPACES}

\section{EDUCACIÓN POPULAR EN SALUD EN CURSO DE GRADO EN ENFERMERÍA: CONST RUCCIÓN DE ESPACIOS PARTICIPATIVOS CURRICULARES}

\author{
Andiara Cossetin ${ }^{1}$ \\ Darielli Gindri Resta ${ }^{2}$ \\ Fernanda Carlise Mattioni ${ }^{3}$ \\ Maria de Lourdes Denardin Budó ${ }^{4}$
}

RESUMO: Objetivo: instigar os estudantes de enfermagem a refletirem sobre práticas pedagógicas a partir da educação popular. Método: relata experiência da construção de espaços curriculares de diálogo sobre o tema educação popular como estratégia de inserção dos estudantes de Enfermagem da Universidade Federal de Santa Maria na realidade social, fomentando possibilidades e desafios do trabalho em saúde. Descreve encontros da disciplina Seminário de Integração Educação e Saúde, que fizeram parte das atividades do Trabalho de Conclusão de Curso no Estágio Supervisionado em Enfermagem II. Resultados: foram cinco encontros, com dinâmicas de grupo e discussões sobre as competências de enfermagem, educação em saúde, Estratégia de Saúde da Família, movimentos sociais, pedagogia da autonomia, educação e educação popular. Conclusão: a vivência curricular apresentou-se como potencializadora de ações pautadas na solidariedade, justiça e participação social, assim como o saber popular pode ser visto como eixo estruturante na organização dos serviços e currículos de graduação.

Descritores: Enfermagem; Educação; Sistema Único de Saúde.

ABST RACT : objective: encourage the nursing student to reflect on educational practices from the popular education. Method: reports the experience of the construction of curricular spaces of dialogue about the theme popular education as strategy for integration the nursing students of Federal University of Santa Maria in social reality, facilitating possibilities and challenges of the health work. Describes the meetings of the discipline Seminar of Integration, Education and Health, which took part of the activities work conclusion course in the Supervised Nursing II. Results: it was realized five meetings with groups dynamics and discussions about the competences of nursing, health education, Family Health Strategy, social movements, pedagogy of autonomy, education and popular education. Conclusion: the curricular experience had to be enhanced in the actions based on solidarity, justice and social participation, as well as the popular know can be seen as structuring axis in the organization of the services and graduation curriculum.

Descriptors: Nursing; Education; Brazilian National Health Care System.

\footnotetext{
${ }^{1}$ Enfermeira. Mestre em Enfermagem pela Escola de Enfermagem da Universidade Federal do Rio Grande do Sul, Grupo Hospitalar Conceição. E-mail: andiaracossetin@gmail.com.

${ }^{2}$ Enfermeira. Doutoranda em Enfermagem pela Escola de Enfermagem da Universidade Federal do Rio Grande do Sul. Docente da Universidade Federal de Santa Maria (UFSM/ CESNORS). E-mail: darielli2004@yahoo.com.br. ${ }^{3}$ Enfermeira. Mestre em Saúde Pública pela Escola Nacional de Saúde Pública Sérgio Arouca, Secretaria Estadual de Saúde do Rio Grande do Sul e Grupo Hospitalar Conceição. E-mail: fcmattioni@yahoo.com.br.

${ }^{4}$ Enfermeira. Doutora em Enfermagem pela Universidade Federal de Santa Catarina. Professor Associado II do Departamento de Enfermagem e do Programa de Pós-Graduação da Universidade Federal de Santa Maria. Email: lourdesdenardin@gmail.com.
} 


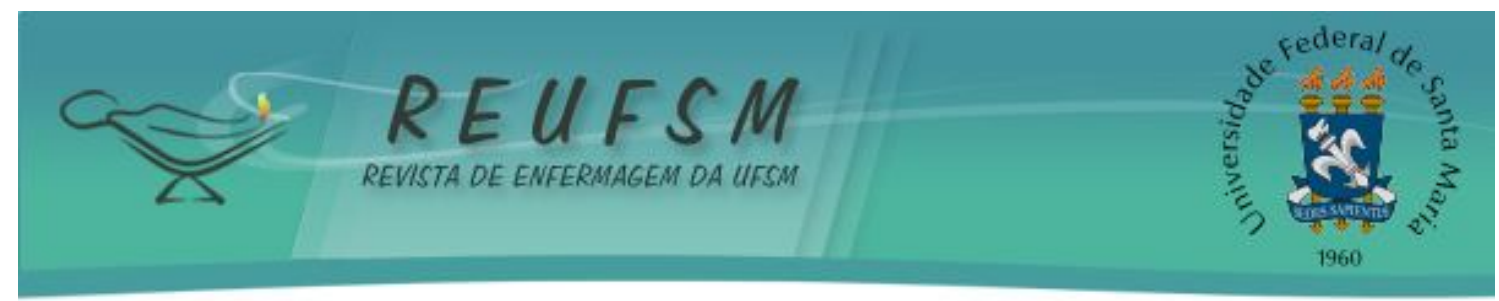

RESUMEN: Objetivo: estimular los estudiantes de enfermería a reflejaren sobre prácticas pedagógicas partiendo de la educación popular. Método: relata la experiencia de la construcción de espacios curriculares de diálogo sobre el tema educación popular como estrategia de inserción de los estudiantes de Enfermería de la Universidade Federal de Santa Maria en la realidad social, promoviendo posibilidades y desafíos del trabajo en salud. Describe los encuentros de la disciplina Seminario de Integración, Educación y Salud, que tomaron parte de las actividades del trabajo de finalización del curso en la Práctica Supervisada en Enfermería II. Resultados: fueran cinco encuentros, con dinámicas de grupo y discusiones sobre las competencias de enfermería, educación en salud, Estrategia Salud de la Familia, movimientos sociales, pedagogía de la autonomía, educación y educación popular. Conclusión: la experiencia curricular fue presentada como capaz de potenciar acciones centradas en la solidariedad, justicia y participación social, así como el saber popular puede ser comprendido como eje de estructuración en la organización de los servicios y currículos de graduación.

Descriptores: Enfermería; Educación; Sistema Brasileño Nacional de Salud.

\section{INTRODUÇÃO}

No sentido de publicizar experiências curriculares inovadoras, este relato evidencia a aproximação dos(as) estudantes do terceiro semestre do Curso de Graduação em Enfermagem da Universidade Federal de Santa Maria (UFSM) com a educação popular em saúde, campo teórico-prático dinâmico e dialético. A educação popular define-se pela e na práxis com ênfase nas questões pedagógicas e metodológicas. Além disso, pode ser incorporada às práticas em saúde de maneira contínua e sistemática, já que implica em momentos de reflexão teórica sobre a prática, confrontando com potencialidade essa sistematização com interpretação e informação sobre essa prática ao formular teorias a partir e não sobre a prática. ${ }^{1}$

0 presente artigo descreve as atividades realizadas nos encontros com esses estudantes de enfermagem na disciplina Seminário de Integração Educação em Saúde. Essas atividades fizeram parte do Trabalho de Conclusão de Curso (TCC) e foram desenvolvidas durante o oitavo semestre no Estágio Supervisionado em Enfermagem II de uma das autoras deste artigo, a qual foi convidada a realizar discussões sobre educação popular nas aulas da disciplina. Essas atividades foram construídas em uma perspectiva problematizadora nos âmbitos do ensino em enfermagem, considerando o olhar dos(as) estudantes no contato com as diversas práticas, culturas e saberes que emergem e circulam nos espaços distantes da estrutura física da academia.

A reflexão sobre a dimensão da atuação do enfermeiro e sua inserção na realidade socialmente construída, produziu momentos de autocrítica e questionamentos em relação à enfermagem enquanto prática, tendo em vista a complexidade e o histórico inerente ao fazer dos trabalhadores de saúde. Com isso, veio à tona a necessidade dos estudantes reconhecerem as possibilidades e as estratégias criativas e sensibilizadoras das ações em saúde. O desafio de inserir o tema educação popular em saúde no ensino possibilitou 0 resgate dos saberes do campo da saúde coletiva, para superar abordagens e metodologias de caráter convencional tanto no ensino como na assistência, compreendendo a enfermagem além das práticas gerenciais, assistenciais e individuais nos serviços.

A motivação das autoras para discussões sobre o tema educação popular no ensino, foi importante para agregar estudantes, trabalhadores da área da saúde, docentes da UFSM e gestores da Secretaria Municipal de Saúde em atividades e ações construídas no processo de elaboração, implementação e avaliação da proposta. 


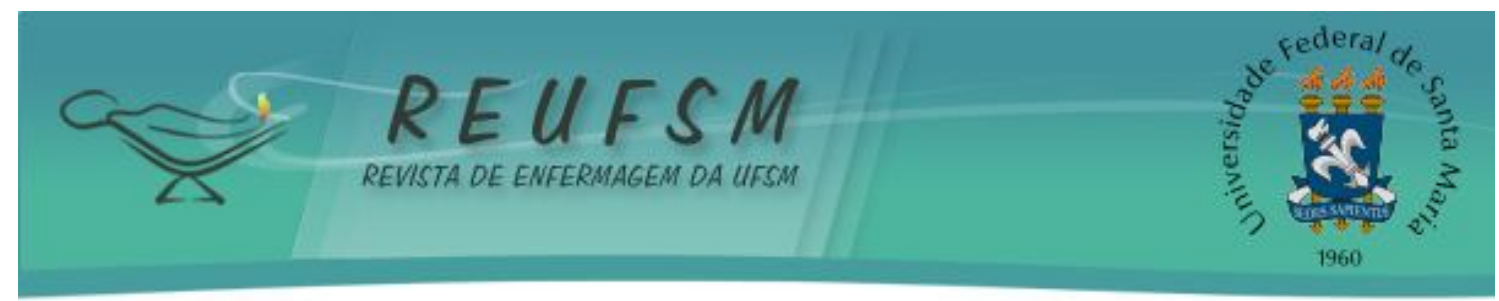

MÉTODO

O estágio de oitavo semestre compreendeu um total de 540 horas-aula, sendo 430 para sua aplicação teórica-prática, tendo como um dos locais da vivência uma sala do Departamento de Enfermagem do Centro de Ciências da Saúde da UFSM, onde ocorreram os encontros com estudantes do terceiro semestre do Curso de Enfermagem, por meio do Seminário de Integração Educação em Saúde. ${ }^{2}$ Para complementar as atividades teóricas produzidas em sala de aula, os estudantes foram convidados a conhecer o contexto da educação popular em saúde no território de abrangência da Estratégia Saúde da Família (ESF) Santo Antão junto a uma comunidade rural de atuação da equipe desse serviço da atenção básica de Santa Maria, Rio Grande do Sul. Esse serviço não era campo de estágio dos alunos de terceiro semestre, mas fez parte do estágio supervisionado em enfermagem II de uma das autoras deste artigo, a qual agendou a visita junto à coordenação do serviço.

A integração dos estudantes junto a moradores desse território favoreceu a imersão no universo da práxis da educação popular em saúde. Essas atividades de discussão sobre educação popular, ocorreram em momentos do Seminário e as vivências na ESF da zona rural, ocorreram em um total de cinco encontros, nos meses setembro e outubro de 2005, nas segundas-feiras durante o turno da manhã com uma turma de 26 estudantes.

Os métodos utilizados foram rodas de conversa em sala de aula, discussões em grupo, apresentação de pressupostos e referenciais teóricos sobre educação popular com recursos audiovisuais, debates, construção de cartazes e elaboração de textos sobre a experiência. As temáticas discutidas foram educação popular em saúde, competências e trabalho no Sistema Único de Saúde (SUS), educação em saúde na ESF, pedagogia da autonomia e movimentos sociais.

\section{Primeiro encontro: competências e trabalho no SUS}

Inicialmente foi realizada a apresentação dos participantes e da proposta do projeto de estágio supervisionado junto aos estudantes presentes, com uma discussão sobre as competências e o trabalho do enfermeiro no SUS. Os estudantes demonstraram interesse em participar do projeto do TCC, já que o tema educação popular ainda não havia sido desenvolvido enquanto problematização junto aos movimentos sociais durante a graduação. Para suscitar a discussão foram apresentadas aos estudantes as diferentes possibilidades de trabalho do enfermeiro e as concepções de saúde ao longo da história, além das possibilidades e conquistas do SUS. A partir disso, foram problematizando 0 conceito ampliado de saúde e sua relação com as atribuições, funções e cargos exercidos pelo(a) enfermeiro(a), nos contextos social, da gestão, da administração, dos cuidados, da cidadania, da política, da assistência, da educação, entre outros. Destacam-se questionamentos em relação à necessidade de mudanças pedagógico-metodológicas nos espaços do ensino, aos desencontros entre discurso e prática como um entrave na práxis do ensino e à educação popular como uma aliada da integralidade em saúde.

A problematização sobre a necessidade de mudança nos currículos dos cursos de graduação da área da saúde levantou discussões acerca da estrutura curricular, a qualificação e o aperfeiçoamento de pessoal para o trabalho no SUS. A permanência dos(as) estudantes em espaços de deliberação acerca dos eixos estruturantes do curso, faz com que esses atores sejam agentes co-responsáveis no processo de ensino em enfermagem. Foram observadas e problematizadas as condições e situações de saúde distantes das bibliotecas e dos referenciais bibliográficos, mas próximas dos usuários do SUS, da comunidade, dos movimentos sociais e das instâncias do controle social. 0 momento propiciou aos estudantes uma reflexão sobre a valorização do saber popular e a 


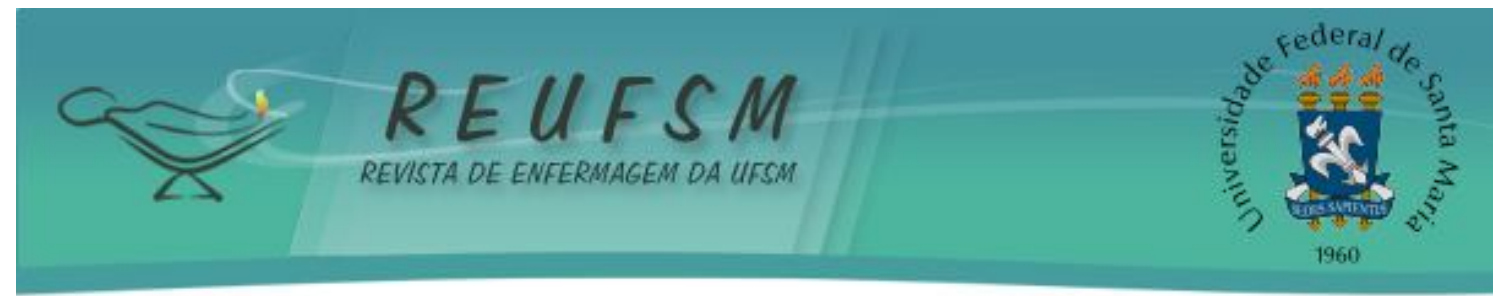

qualificação da gestão e do planejamento em saúde, a partir do território e das necessidades da população.

A importância e necessidade de estimular os cidadãos por intermédio das ações de enfermagem, vinculam-se não só com "processos pedagógicos e de protagonismos, mas, também, com a ausência do Estado e com o não cumprimento de seu papel para 0 desenvolvimento de políticas públicas". ${ }^{3: 364}$ No contexto do trabalho em enfermagem, a apropriação de metodologias de ensino problematizadoras pressupõe a aproximação com movimentos sociais, coletivos e entidades organizadas da sociedade para atuar na defesa e promoção da qualidade de vida e dos direitos fundamentais. "Isso pode significar a reivindicação de espaço na estrutura existente, mas pode também representar 0 engajamento na luta por rupturas e pela busca de novas possibilidades de organização da vida comum". ${ }^{4: 300} \mathrm{O}$ grande diferencial da educação popular é o "rompimento com espaços formais da educação e a busca por aproximação entre saberes de diferentes lugares da sociedade e da cultura. A escola passa a ser um entre muitos outros espaços onde as pessoas se formam". .:20

Os trabalhadores de enfermagem podem inventar modos de atuar com abordagens convergentes com a educação popular quando assumem responsabilidades na construção de proj etos terapêuticos para o cuidado integral em saúde. Por isso, passam a ser fundamentais as articulações com atores circulantes nos espaços de participação popular e redes de apoio aos usuários, dando vida ao cotidiano do trabal ho também a partir desses espaços.

Nesse momento, os princípios e diretrizes do SUS foram defendidos como sustentadores das práticas, fortalecendo o compartilhar das responsabilidades, a ética e a sensibilidade no cuidado em enfermagem junto à população. Os estudantes puderam problematizar sobre sua participação na formação política durante a graduação, sendo fundamental relacionar suas ações, críticas, reflexões, responsabilidades, direitos e deveres como cidadãos.

\section{Segundo encontro: espaços de educação em saúde nos serviços}

No segundo encontro, o tema desenvolvido foi educação em saúde no contexto da ESF. Para fomentar as discussões foi lançada a seguinte questão problematizadora: qual a importância e o espaço da educação em saúde na ESF? Percebeu-se que tanto a educação em saúde como a ESF resgatam e retomam a atenção básica como espaço estruturante do SUS por intermédio da promoção da saúde. Esses temas são complexos e necessitam debates anteriores, iniciados previamente nas aulas das disciplinas Saúde Coletiva I, Saúde Coletiva II e tiveram aprofundamento nas disciplinas Seminário de Integração Educação e Saúde e Saúde Coletiva III. Os estudantes manifestaram suas ideias por meio de cartazes, com o uso de recursos como papel pardo, pincéis, tesouras e recortes de revistas. Durante 20 minutos, divididos em quatro grupos, os estudantes dialogaram e elaboraram cartazes que descreviam as relações entre educação em saúde e a ESF. Dentre os recortes de revistas utilizados pelos estudantes estão imagens de estudantes, demonstrando que a coletividade pode ser potencializadora das práticas de educação em saúde junto aos usuários do SUS; moradias na zona rural, ilustrando a aproximação entre população urbana e rural e as possibilidades do acesso à educação em saúde na ESF; um homem afrodescendente, como respeito às diferenças de cor, crença e cultura como uma estratégia de aproximação entre estudantes e sociedade; corpo e coração de um indivíduo, como crítica às práticas na ESF e as ementas de disciplinas básicas dos semestres iniciais da graduação que enfatizam conceitos de saúde centrados na ausência de doença e na cura dos órgãos não sadios, partes do paciente ou pedaços doentes, descontextualizadas das questões subjetivas, institucionais, históricas, culturais e sociais que envolvem o cuidado. 


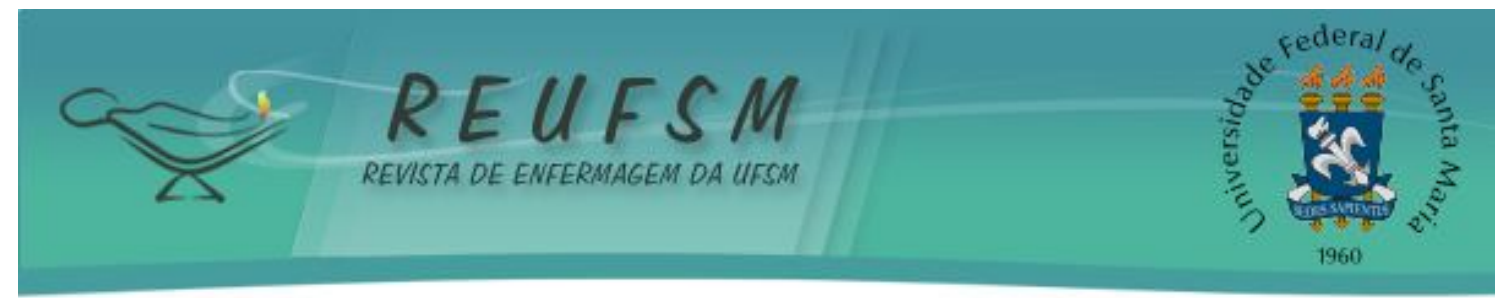

Após a apresentação dos significados das imagens coladas nos cartazes pelos integrantes dos grupos, a turma foi instigada a refletir sobre a necessidade de ações de transformação social nos espaços de educação em saúde na ESF. Esta é considerada uma estratégia com foco no cuidado à saúde das famílias brasileiras, através das equipes de saúde da família, provocando a reordenação do modelo de atenção no SUS. Foi criada como um projeto dinamizador, iniciado em 1994, com o Programa de Saúde da Família, num processo de transformação histórica referente à organização do sistema de saúde e substituição dos serviços tradicionais na atenção básica dos municípios, buscando uma melhoria dos indicadores de saúde e das condições e qualidade de vida da população. ${ }^{6}$

Nessa perspectiva, a discussão ampliou-se para as relações entre docentes, estudantes e trabalhadores da ESF, além do comprometimento e responsabilização desses atores com as políticas de saúde e educação, junto à necessidade de respeito aos valores, cultura e modos de vida. Foi debatido sobre a acomodação dos docentes e discentes frente à realidade socialmente construída e o papel que estudantes e professores do Curso de Enfermagem assumem na universidade, nos serviços de saúde e na sociedade.

\section{Terceiro encontro: educação e educação popular}

No terceiro encontro, a discussão sobre educação e educação popular baseou-se na leitura prévia do texto Educação: um tesouro a descobrir, do relatório da Comissão Internacional da Organização das Nações Unidas para Educação, Ciência e Cultura. Nesse documento, que trata da Educação para o século XXI, são enfatizados os quatro pilares da educação: aprender a conhecer, aprender a fazer, aprender a viver juntos e aprender a ser. ${ }^{7}$

Os estudantes puderam compreender que é necessário valorizar todas as ocasiões de aprofundar saberes e a visão de mundo, tão importantes na descoberta de si mesmo e do outro enquanto suj eitos sociais em interação. Na ocasião, foram debatidos pensamentos de Paulo Freire, a estruturação da educação popular nos anos 50 por parte de intelectuais e educadores ligados à igreja católica, a aproximação entre Ministério da Saúde e os movimentos sociais, a práxis como facilitadora das ações de saúde e os movimentos sociais com ênfase no movimento estudantil e suas possibilidades.

A construção histórica dos movimentos, experiências e articulações referentes à educação popular e saúde constitui-se um desafio como sistematização, sendo que momentos históricos importantes foram publicados em textos de Eymard Mourão Vasconcelos, Eduardo Navarro Stotz, J osé Ivo dos Santos Pedrosa, Victor Valla, entre outros pesquisadores sobre o tema. Nesse contexto, a Articulação Nacional de Educação Popular em Saúde foi criada em 1991 no I Encontro Nacional de Educação Popular em Saúde, realizado em São Paulo, passando a denominar-se Rede de Educação Popular e Saúde em 1998. Porém, a educação popular em saúde emergiu como movimento social no Congresso de Saúde Coletiva da Associação Brasileira de Pós-Graduação em Saúde Col etiva realizado em Salvador, nos meses de julho e agosto de $2000 .{ }^{8}$ Os momentos históricos podem ser aprofundados com a leitura de estudos, pesquisas, artigos, projetos, relatórios, livros e documentos que abordam a temática.

0 resgate da educação popular, no plano institucional, constitui-se na construção do SUS com universalidade, integralidade, equidade e participação social. Esses princípios orientadores da Reforma Sanitária têm sentido no cotidiano das pessoas como uma estratégia política e metodológica do Ministério da Saúde. A educação popular trabalha na perspectiva da "integralidade de saberes e de práticas, pois proporciona o encontro com outros espaços, com outros agentes e com tecnologias que se colocam a favor da vida, da dignidade e do respeito ao outro". 9:9 Representa outra cultura de relação com as classes populares que supera os aspectos autoritários e normatizadores da educação em saúde 


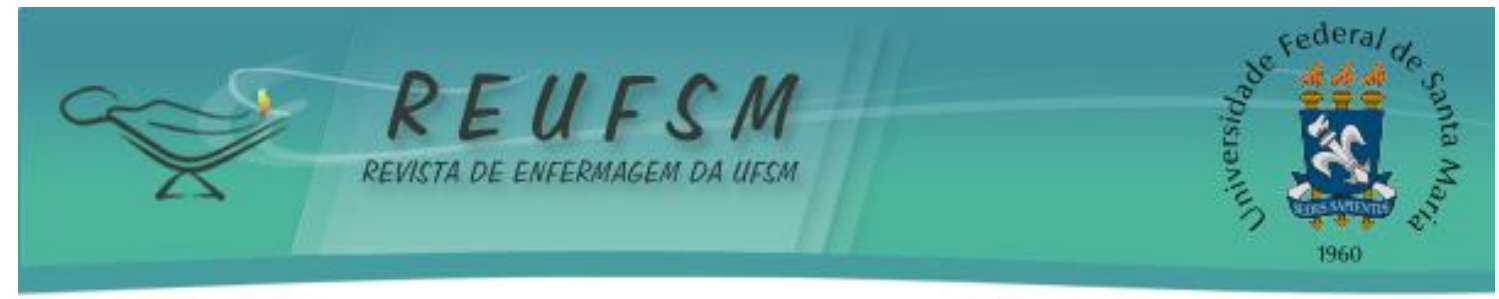

tradicional. ${ }^{10} \mathrm{~A}$ educação popular preconiza que o conhecimento pode ser construído de maneira compartilhada com pessoas, comunidades e serviços de saúde. ${ }^{11}$

Neste encontro, os estudantes puderam perceber as relações entre os termos educação, educação em saúde e educação popular em saúde, vislumbrando as potencialidades da educação popular enquanto auxiliar na recriação e reinvenção das práticas nos serviços de saúde, valorizando o saber da população. Assim o conhecimento pode ser entendido como uma estratégia utilizada pelos trabalhadores nos serviços, transformando as ações de saúde em ações educativas, a partir da compreensão da educação como um processo de construção coletiva. ${ }^{12}$

\section{Quarto encontro: visita ao assentamento Mariguela}

No quarto encontro, foram realizadas as visitas a USF do Distrito Santo Antão e ao Assentamento Mariguela, previamente pactuadas com os estudantes do terceiro semestre de enfermagem, na qual os participantes vivenciaram um espaço de troca de saberes com integrantes do Movimento dos Trabalhadores Sem Terra (MST). O grupo chegou ao salão central do assentamento, onde um dos integrantes do MST propôs uma rodada de apresentações. Por intermédio de uma conversa informal, o integrante do MST foi convidado a relatar sobre a vida dos assentados do distrito Santo Antão e a organização das famílias. Discutiu-se sobre os desafios enfrentados pelos assentados do Mariguela, incluindo um momento de apresentação da sede e das atividades cotidianas, assim como das dificuldades de financiamento, organização, transporte e de relação entre assentados.

o coordenador da discussão, integrante do MST, resgatou o histórico do acampamento no município de J óia-RS, onde havia uma equipe responsável pelo transporte até instituições de saúde, pelos tratamentos alternativos e pela busca de medicações e materiais para o cuidado dos acampados, entre outras atividades. Ainda, esclareceu 0 processo de saída do acampamento para o assentamento, incluindo os critérios para receber a terra como, por exemplo, morar em agrovila, trabalhar coletivamente, desenvolver a agroecologia e participar de um sorteio. Em relação à organização interna dos acampamentos, além da equipe de saúde, contavam com o trabalho da equipe da educação, da segurança, da alimentação, da limpeza, da montagem das barracas, etc.

Segundo os moradores do Assentamento Mariguela, cada uma das equipes era representada por dois integrantes que faziam parte da coordenação geral, sendo escolhidos pelo coletivo. Ressaltaram o significado de coletividade como um processo que alguns trabalhadores rurais fazem a opção de sair do assentamento para a produção individual em outros locais e que a palavra coletivo envolve o respeito a essa atitude e a articulação de setores da sociedade com diferentes culturas e locais de trabalho numa rede.

A integração entre estudantes e trabalhadores rurais foi determinante pela vivência, já que poucos conheciam sobre o MST e muitos deles tinham apenas a visão construída a partir da mídia, muitas vezes fragmentada do contexto mais amplo, criminalizada e distorcida. Depois disso, fez-se pausa para um almoço com alimentos e bebidas orgânicas produzidos na própria sede do assentamento. No encerramento das atividades do dia, realizou-se a oficina sobre o MST, com a coordenação de um militante do movimento há sete anos, sendo dois anos em acampamento e cinco em assentamento.

\section{Quinto encontro: a obra pedagogia da autonomia}

No quinto encontro e último dia de aula, do segundo semestre de 2005, o grupo foi dividido em três subgrupos para as apresentações sobre a obra Pedagogia da Autonomia de 


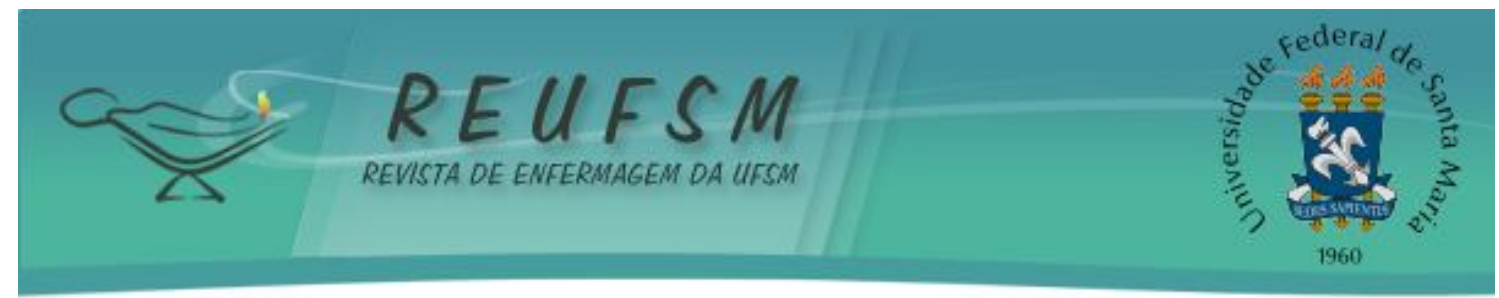

Paulo Freire com os seguintes capítulos: Não há docência sem discência (grupo I), Ensinar não é transferir conhecimento (grupo II) e Ensinar é uma especificidade humana (grupo III). Os estudantes apresentaram os capítulos sob a forma de slides do programa Power Point do Windows 2003, contendo resumos e esquemas facilitadores de entendimento e interação com os demais colegas. A contextualização sobre a educação como uma "via de mão dupla" em que deve haver respeito pela "leitura de mundo" e saberes dos educandos foi debatida.

A vivência prática no Assentamento Mariguela foi relacionada com os pressupostos de Freire, quando os estudantes relataram sobre a importância da mobilização popular e do respeito frente aos saberes populares socialmente construídos na prática comunitária. Nesse momento, a discussão sobre práxis entrou em cena, fazendo os estudantes construírem formas dinâmicas de transportar a prática para os espaços de reflexão teórica e vice-versa, ressaltando que isso também faz parte do método pedagógico de Paulo Freire. Outra questão relevante são as parcerias entre o Estado e o MST na realização de seus programas de formação e a importância da educação popular, considerando que o MST resiste à escolarização no sistema de ensino regular, mesmo na zona rural, já que a preparação está focada para os educandos trabalharem no campo e continuarem na luta pela justiça social. ${ }^{4}$

Durante a atividade, na exposição de idéias do grupo I, os estudantes enfatizaram alguns fragmentos do capítulo "Não há docência sem discência" focalizando a discussão na relação educador-educando, preconceito em relação às práticas pedagógicas democráticas na educação e o enfrentamento dos desafios da formação em enfermagem. Na mesma perspectiva agregaram-se ao debate os grupos II e III, os quais apresentaram suas reflexões acerca da leitura realizada, fomentando as idéias do autor sobre educação ao comparar o ato de educar com o de viver, já que nada está acabado e pertence a uma história em processo de transformação com diferentes atores sociais que ressignificam e reconstroem as práticas educativas e os modos de vida. A avaliação sobre a importância da leitura da obra após a visita foi motivante, já que permitiu a visualização de diferentes integrações como ensino e serviço, individual e coletivo, social e cultural, urbano e rural, saúde e educação, científico e popular. Nesse sentido, a ação transformadora da enfermagem do cuidado perpassa uma aproximação com questões referentes ao conhecimento científico que já estão instituídas nos serviços de saúde e espaços de formação, sendo fundamental entrelaçar saber científico e saber popular, em movimento espiral, já que podem se cruzar e se distanciar, com suas características e especificidades. ${ }^{13}$

\section{CONSIDERAÇÕES FINAIS}

A experiência integradora possibilitou a inclusão de uma vivência curricular na realidade dos movimentos sociais organizados e contou com o apoio da coordenadora e da docente da disciplina, dos estudantes de enfermagem, dos trabalhadores da equipe da ESF e dos assentados do MST. Propiciou um aprofundamento sobre a temática educação popular na matriz curricular do Curso de Enfermagem, especialmente no terceiro período da graduação. A educação popular é um processo que envolve compromisso social com a transformação das estratégias pedagógicas, a partir da inclusão da população enquanto educadora, levando em consideração as necessidades locais da população.

Além da transformação das práticas e formação na área da saúde, a educação popular pode impulsionar processos de educação permanente em saúde, na construção de projetos políticos pedagógicos nas universidades e projetos terapêuticos com os usuários dos serviços de saúde. 0 método criado por Paulo Freire está longe de ser caracterizado como educação informal, enfatizando a construção de saberes e a interação cultural, de maneira ampliada e compartilhada, além de fomentar a organização política e negociação 


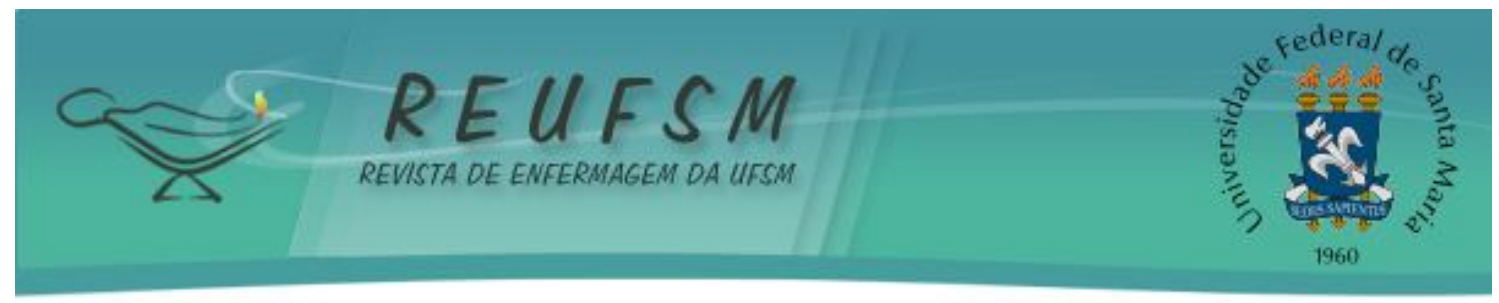

entre os atores sociais na busca da resolução de determinado problema social. Ao mesmo tempo, a educação popular enquanto campo científico está constituindo-se com "princípios básicos que o tornam diferenciado dos demais e que servem de elementos para identificar aquilo que lhe é próprio, criando e alimentando sentimentos de pertencimento por parte dos envolvidos". 14:306 Salienta-se a importância da construção de estratégias de "disputa dos distintos projetos políticos junto à sociedade. Tal caminho se tornaria mais difícil, entretanto, quando encontramos os trabalhadores com vínculos empregatícios precários", situação fragilizadora destes atores em relação aos que ocupam "posição de governo". 15:16

No que se refere à integração dos estudantes de enfermagem com os movimentos sociais organizados, o proj eto contribuiu para que os docentes e discentes repensassem os processos político-pedagógicos e as estruturas curriculares dos cursos de graduação na área da saúde, na lógica da educação permanente. Já no que se refere à educação popular em saúde, quanto mais conhecermos e tivermos contatos com abordagens pedagógicas dialógicas, mais compreenderemos a complexidade da horizontalidade dos saberes, poderes e relações nos encontros que envolvem a organização dos grupos sociais e suas construções históricas, ideológicas e sociais.

\section{REFERÊNCIAS}

1. Hurtado CN. Educar para transformar: transformar para educar. Petrópolis: Vozes; 1993.

2. Cossetin A. Educação popular em saúde: uma estratégia na relação ensino-serviçogestão-comunidade. Santa Maria, 2006. 100 f. Trabalho de Conclusão de Curso (Graduação) - Universidade de Santa Maria, Centro de Ciências da Saúde, Departamento de Enfermagem; 2006.

3. Malfitano APS, Lopes RE. Educação popular, ações em saúde, demandas e intervenções sociais: o papel dos agentes comunitários de saúde. Cad. CEDES. 2009;29(79):361-72.

4. Streck DR. Entre emancipação e regulação: (des)encontros entre educação popular e movimentos sociais. Rev bras educ. 2010;15(44):300-10.

5. Streck DR. José Martí e a educação popular: um retorno às fontes. Educ pesq. 2008;34(1):11-25.

6. Ministério da Saúde (BR). Departamento da Atenção Básica. Diretriz conceitual da atenção básica e saúde da família [online]. Brasília (DF): MS; 2004 [acesso em 2011 jun 27]. Disponível em: http:// dab. saude.gov. br/ atencaobasica. php.

7. Delours J, coordenador. Educação um tesouro a descobrir: relatório para a UNESCO da Comissão Internacional sobre Educação para o século XXI. São Paulo (SP): Cortez; Brasília (DF): MEC, UNESCO; 2006.

8 Stotz EN, David H, Wong-un JA. Educação popular e saúde: trajetória, expressões e desafios de um movimento social. Rev APS [periódico na internet]. 2005 [acesso em 2011 jul 27]. Disponível em: http:// www. nesp.unb.br/ eps/ educacaopopular.pdf.

9. Ministério da Saúde (BR). Secretaria de Gestão Estratégica e Participativa. Departamento de Apoio a Gestão Participativa. Cad educ pop saúde [online]. Brasília (DF): MS; 2007 [acesso em 2011 ago 2]. Disponível em: http:/ / portal.saude.gov.br/ portal/ arquivos/ pdf/ caderno_de_educacao_popular_e_saude.pdf.

10. Valla V. Educação popular, saúde comunitária e apoio social numa conjuntura de globalização. Cad saúde pública. 1999; 15(2). 


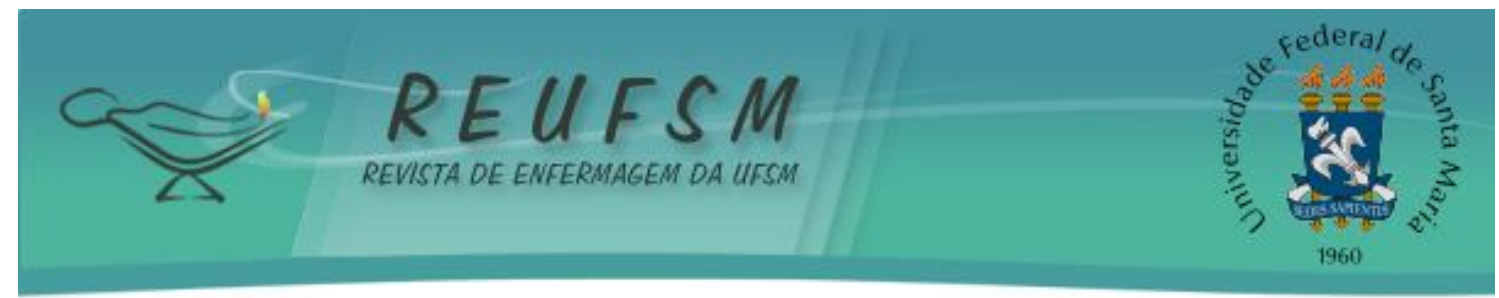

11. Vasconcelos EM. Educação popular: instrumento de gestão participativa dos serviços de saúde. In: Ministério da Saúde (BR). Cadernos de educação popular e saúde. Brasília: Ministério da Saúde; 2007.

12. Albuquerque $P C$, Stotz EN. A educação popular na atenção básica à saúde no município: em busca da integralidade. Interface comun saúde educ. 2004; 15(8):259-74.

13. Alvim NAT, Ferreira MA. Perspectiva problematizadora da educação popular em saúde e a enfermagem. Texto \& contexto enferm. 2007;16(2):315-19.

14. Pedrosa JIS. Educação popular em saúde e gestão participativa no Sistema Único de Saúde. Rev APS. 2008;11(3):303-13.

15. Gomes LB, Merhy EE. Compreendendo a educação popular em saúde: um estudo na literatura brasileira. Cad saúde pública. 2011;27(1):7-18.

Data de recebimento: 19/08/2011

Data de aceite: 20/12/2011

Contato com o autor responsável: Andiara Cossetin.

Endereço: Rua Marechal Frota, 71, Cristo Redentor, Porto Alegre, RS.

CEP 91350030

E-mail: andiaracossetin@gmail.com 